\title{
The Accounting Methods of the Local Government Department Output by Factor Analysis
}

\author{
Haoyuan Zhong ${ }^{1}, \&$ Guangming Deng ${ }^{1,2}$ \\ ${ }^{1}$ College of Science, Guilin University of Technology, Guilin, China \\ ${ }^{2}$ Guangxi Key Laboratory of Spatial Information and Geomatics, Guilin, China \\ Correspondence: Guangming Deng, College of Science, Guilin University of Technology, Guilin, China. E-mail: \\ dgm@glut.edu.cn
}

Received: March 1, 2014 Accepted: March 20, 2014 Available online: April 8, 2014

doi:10.11114/aef.v1i1.363 URL: http://dx.doi.org/10.11114/aef.v1i1.363

\begin{abstract}
In this paper, using the 2011 national economic accounting data of the provinces, we evaluated the government department performance by factor analysis. And then calculated the local government department's total output taking advantage of the labor production efficiency. And the labor production efficiency of government department concludes the performance information. Which will improved the method of accounting government department's output by cost.
\end{abstract}

Keywords: government's output accounting, factor analysis, performance, labor production efficiency

\section{Introduction}

Government departments afford nonmarket services, so the government department's total output has been estimated by the total cost in the service, namely Input substitution method. But this method has a lot of defects, such as: changing the essence of the "output" in the national economy index, and locking the government department of labor productivity is zero, and then influence the authenticity of the gross domestic product (GDP) growth rate. Someone also wants to account government output by output indexes but there are lots of problems, such as: government department contains a lot of industries, and each industry has different output indicator systems. And that the output can be divided into marketability output and nonmarket output, nonmarket output is hard to calculate and so on. For the output accounting of government departments, we should use the market information as far as possible. And the improvement of the accounting methods shouldn't give up.

\section{Data and Variables}

\subsection{The data source}

This paper uses the raw data from the national bureau of statistics 2011 statistical yearbook.

\subsection{Variable Selection}

On the basis of existing research and the actual situation of China, considering the data 's activeness and consistency, this article selected the indexes are as follows:

(1) Input indicators

Fiscal expenditure system in China includes the central fiscal expenditures and the local fiscal expenditures, but the central government is responsible for the external large fiscal spending, like national defense, diplomacy. And local government is responsible for the general local infrastructure, education and health care, and other areas of the smaller externality. This article studies the local government department's output accounting methods, so choosing the local fiscal budget spending as input indicators.

(2) Output indicators

According to fiscal expenditure and government function of local government departments, this article selected output indexes are in regard to the economy, infrastructure, energy conservation, environmental protection, medical and health care, education and other aspects. 
Table 1. Local government fiscal expenditure performance evaluation index system

\begin{tabular}{cl}
\hline The primary indicators & The secondary indicators \\
\hline \multirow{2}{*}{ Economic } & X1 Total fixed asset investment (/ billion /) \\
& X6 The added value of ecological-economic (/billion/) \\
& X7 Total retail sales of consumer goods (/billion/) \\
& X3 urban residents' per-capita annual income (/RMB/) \\
\hline & X4 Per capita green area \\
X8 Technical market turnover (/ billion/) \\
Infrastructure, & X9 The number of town worker attend endowment insurance \\
education, science and & X10 The number of full-time teachers for elementary school \\
technology, social & X11 With public transport vehicles per ten thousand people \\
& X12 The public library total capacity growth \\
\hline $\begin{array}{c}\text { Environmental } \\
\text { protection and energy } \\
\text { conservation and }\end{array}$ & X2 Energy consumption per unit GDP fell (such as value) (\%) \\
emissions reduction & X1 City daily sewage treatment capacity
\end{tabular}

\section{Theory of Analysis Method}

We use factor analysis to research financial expenditure performance of local government departments. Then define a labor productivity of ministry by applying expenditure performance. Finally, we can calculate the output of government department by labor productivity.

\subsection{Factor Analysis Theory}

Factor analysis is the study of the correlation of a set of variables, we can find the few "factors" instead of comprehensive original variables. And a few factors can reflect most of the original variable information, with purpose of reducing the number of variables, the mathematical model can be writen as follows:

$$
\left\{\begin{array}{c}
X_{1}=a_{11} F_{1}+a_{12} F_{2}+\cdots+a_{1 m} F_{m}+\varepsilon_{1} \\
X_{2}=a_{21} F_{1}+a_{22} F_{2}+\cdots+a_{2 m} F_{m}+\varepsilon_{2} \\
\cdots \\
X_{p}=a_{p 1} F_{1}+a_{p 2} F_{2}+\cdots+a_{p m} F_{m}+\varepsilon_{p}
\end{array}\right.
$$

For the model expressed as matrix form:

$$
X=A F+\varepsilon
$$

$\mathrm{X}$ as observable index vector; $\mathrm{F}$ as an observation factor variables; $\mathrm{A}$ as the factor loading matrix; $\varepsilon_{i}$ as a special factor vector.

And to meet: $(1) m<p ; \quad(2) \operatorname{COV}(F, \varepsilon)=0(3) F_{1} \cdots F_{m}$ have independence and homogeneity of variance. $\varepsilon_{1}, \varepsilon_{2}, \ldots, \varepsilon_{p}$ have independence and heteroscedasticity.

\subsection{Factor analysis steps}

(1) Data standardization

Data standardization formula:

(2) Data verification

$$
x_{i k}^{*}=\frac{x_{i k}-\overline{x_{i}}}{\sqrt{D\left(x_{i}\right)}}
$$

Factor analysis requires strong correlation in the original variables, otherwise cannot synthesize a few public variables to reflect common characteristics. This article uses the KMO and Bartlett ball test. It is based on the variable correlation coefficient matrix, and the statistic test carried out the determinant of the correlation coefficient matrix. If the value is bigger, and its corresponding concomitant probability value is less than the significance level, then reject the null hypothesis. The data is suitable for factor analysis; On the contrary, it is not suitable for factor analysis.

(3) Extracting factors

In this paper, we are using principal component analysis method. 
(4) Factor rotation

This Article uses the varimax to rotate factors, each factor has the minimum number of variables with the highest load, simplifying the interpretation of the factors. Get the matrix:

$$
B=\widehat{A} T
$$

$\widehat{A}$ as the preceding $m$ lists of $A, T$ as the orthogonal matrix

The factor model:

$$
\left\{\begin{array}{l}
\tilde{x}_{1}=b_{11} F_{1}+\cdots+b_{1 m} F_{m} \\
\cdots \cdots \cdots \cdots \cdots \cdots+\cdots \\
\tilde{x}_{p}=b_{p 1} F_{1}+\cdots+b_{p m} F_{m}
\end{array}\right.
$$

(5) Calculate the factor score

The factor score formula:

$$
\hat{F}=A^{\mathrm{T}} R^{-1} X
$$

( $A$ as the factor loading matrix, $R$ as the correlation coefficient matrix, $X$ as the primitive variable vector)

\section{The Empirical Analysis of Factor}

\subsection{The Feasibility Test Results}

Using SPSS statistical software and the results are as follows:

Table 2. KMO and Bartlett's Test

\begin{tabular}{lll}
\hline Kaiser-Meyer-Olkin Measure of Sampling Adequacy. & .731 \\
\hline Bartlett's Test of Sphericity & Approx. Chi-Square & 363.388 \\
& df & 78
\end{tabular}

Sig. .000

The table 2 shows that the KMO value is 0.731 , reaching the standard feasibility. And Bartlett sphericity test value is 363.388 , significance value of 0.00 is far less than the significance level of 0.05 , therefore reject the null hypothesis, so the original data is fit for factor analysis.

\subsection{Factor Extraction}

Table 3. Total Variance Explained

\begin{tabular}{lcccccc}
\hline & \multicolumn{3}{c}{ Initial Eigenvalues } & \multicolumn{3}{c}{ Extraction Sums of Squared Loadings } \\
\cline { 2 - 6 } Component & Total & \% of Variance & Cumulative $\%$ & Total & \% of Variance & Cumulative \% \\
\hline 1 & 6.053 & 46.560 & 46.560 & 6.053 & 46.560 & 46.560 \\
2 & 2.638 & 20.294 & 66.853 & 2.638 & 20.294 & 66.853 \\
3 & 1.058 & 8.140 & 74.994 & 1.058 & 8.140 & 74.994 \\
4 & 1.005 & 7.730 & 82.724 & 1.005 & 7.730 & 82.724 \\
5 & .807 & 6.207 & 88.930 & & & \\
6 & .515 & 3.965 & 92.895 & & & \\
7 & .287 & 2.211 & 95.107 & & & \\
\hline
\end{tabular}

This paper used principal component analysis method to extract factors, and the eigenvalues of extracted factor is greater than 1. The table of Total Variance Explained shows that eigenvalues of the first four component are greater than 1 and the cumulative contribution rate has reached $82.724 \%$.It's said that the first four factors include mainly information of all indicators. 
Table 4. Component Matrixa

\begin{tabular}{|c|c|c|c|c|}
\hline \multirow{2}{*}{ Variables } & \multicolumn{4}{|c|}{ Component } \\
\hline & 1 & 2 & 3 & 4 \\
\hline X1 Total fixed asset investment (billion) & .918 & -.190 & .061 & .124 \\
\hline $\mathrm{X} 2$ Energy consumption per unit GDP fell (such as value) (\%) & .317 & .179 & .852 & .002 \\
\hline X3 Urban residents' per-capita annual income (RMB) & .419 & .760 & .049 & .029 \\
\hline X4 Per capita green area & .306 & -.117 & -.215 & .813 \\
\hline X5 Industrial pollution control investment (Million) & 643 & -.330 & .148 & .371 \\
\hline X6 The added value of ecological-economic (billion) & .804 & -.451 & .107 & -.020 \\
\hline X7 Total retail sales of consumer goods (billion) & .981 & .118 & -.069 & -.010 \\
\hline X8 Technical market turnover (billion) & .115 & .866 & .215 & .124 \\
\hline X9 The number of town worker attend endowment insurance & 919 & .216 & -.133 & -.132 \\
\hline X10 The number of full-time teachers for elementary school & .770 & -.433 & .130 & -.183 \\
\hline X11 With public transport vehicles per ten thousand people & .090 & .787 & -.159 & .154 \\
\hline X12 The public library total capacity growth & .768 & .149 & -.342 & -.265 \\
\hline X13 City daily sewage treatment capacity & .878 & .166 & -.136 & -.172 \\
\hline
\end{tabular}

Extraction Method: Principal Component Analysis.

4 components extracted.

The table 4 shows that there are 8 variables on the first factor of the load which is very high, and can't explain these variables well, and the actual meaning of the other three factors are vague, so is needed factor rotation, making the factors have good practical significance.

\subsection{The Results of Factor Rotation}

Table 5. Total Variance Explained

Initial Eigenvalues

Components Total \% of Variance Cumu

\begin{tabular}{cccccccccc}
\multicolumn{2}{c}{ Components } & Total & \% of Variance Cumulative $\%$ & Total & $\%$ of Variance & Cumulative $\%$ & \multicolumn{1}{c}{ Total } & \% of Variance Cumulative \% \\
\hline 1 & 6.053 & 46.560 & 46.560 & 6.053 & 46.560 & 46.560 & 5.453 & 41.944 & 41.944 \\
2 & 2.638 & 20.294 & 66.853 & 2.638 & 20.294 & 66.853 & 2.631 & 20.238 & 62.182 \\
3 & 1.058 & 8.140 & 74.994 & 1.058 & 8.140 & 74.994 & 1.405 & 10.809 & 72.991 \\
4 & 1.005 & 7.730 & 82.724 & 1.005 & 7.730 & 82.724 & 1.265 & 9.732 & 82.724 \\
5 & .807 & 6.207 & 88.930 & & & & 5.453 & & \\
\hline
\end{tabular}

Table 6. Rotated Component Matrixa

\begin{tabular}{lcccc}
\hline & \multicolumn{4}{c}{ Components } \\
\cline { 2 - 5 } & 1 & 2 & 3 & 4 \\
\hline X1 Total fixed asset investment (billion) & -.045 & -.728 & -.055 & .315 \\
X2 Energy consumption per unit GDP fell (such as value) $(\%)$ & .157 & .127 & -.029 & .885 \\
X3 Urban residents' per-capita annual income (RMB) & .314 & .759 & -.047 & .228 \\
X4 Per capita green area & .116 & .080 & .887 & -.114 \\
X5 Industrial pollution control investment( Million) & .517 & -.198 & .551 & .263 \\
X6 The added value of ecological-economic (billion) & .791 & -.356 & .252 & .207 \\
X7 Total retail sales of consumer goods (billion) & .932 & .227 & .198 & .130 \\
X8 Technical market turnover (billion) & -.030 & .883 & -.033 & .268 \\
X9 The number of town worker attend endowment insurance & .907 & .299 & .054 & .058 \\
X10 The number of full-time teachers for elementary school & .799 & -.333 & .103 & .162 \\
X11 With public transport vehicles per ten thousand people & -.002 & .780 & .005 & -.015 \\
X12 The public library total capacity growth & .838 & .234 & -.066 & -.210 \\
X13 City daily sewage treatment capacity & .884 & .243 & .018 & .037 \\
\hline Extraction Method: Principal Compont
\end{tabular}

Extraction Method: Principal Component Analysis.

Rotation Method: Varimax with Kaiser Normalization.

a. Rotation converged in 6 iterations. 
The table 5 shows that the variance contribution rate of the first factor is the biggest, so the first component needs to explain the most of the variables. The variance contribution rate of the first component is still high, but some has spread to other factors. Rotated Component Matrix is shown in table 6.

Table 6 shows that the first component has higher loads in Total fixed assets investment, The added value of ecological-economic (/billion/), Total retail sales of consumer goods (/billion/), The number of town worker attend endowment insurance, The number of full-time teachers for elementary school, The public library total capacity growth, City daily sewage treatment capacity. Though the last four indicators are not economic indicators, the" economic base determines the superstructure," and these indicators can reflect the level of the economy development. So the first component can be seen as a contribution of expenditure to economic. For the second component, Urban residents' per-capita annual income (RMB), Technical market turnover (/billion/), with public transport vehicles per ten thousand people have higher loads. So the second component can be considered as the expenditure contribution in science and technology development. Only the per capita green area 2011 (sqm / person) variables have the higher load on the third component. So it can be considered the contribution of fiscal spending on environmental improvements. The fourth component is the contribution of fiscal spending on energy conservation because of the higher load on Energy consumption per unit GDP fell (such as value)(\%)

\subsection{The Factor Score and Ranking}

The factor scores and rankings are shown in table 7:

Table 7. Factor scores and Rankings

\begin{tabular}{ccccccc}
\hline District & F1 & F2 & F3 & F4 & F & ranking \\
\hline Guangdong & 3.15 & 0.95 & -0.38 & -1.24 & 1.63 & 1 \\
Jangsu & 2.27 & 0.79 & 0.60 & -0.52 & 1.36 & 2 \\
Shandong & 1.34 & -0.31 & 3.07 & 1.02 & 1.12 & 3 \\
Beijing & -0.89 & 4.10 & -0.01 & 1.23 & 0.70 & 4 \\
Zhejiang & 1.06 & 0.97 & -0.11 & -0.65 & 0.68 & 5 \\
Sichuan & 0.82 & -0.43 & -0.35 & 0.21 & 0.29 & 6 \\
Henan & 1.16 & -1.41 & -0.80 & 1.01 & 0.26 & 7 \\
Shanghai & -0.05 & 1.59 & -1.76 & 0.78 & 0.22 & 8 \\
Hebei & 0.29 & -0.67 & 1.26 & 0.54 & 0.21 & 9 \\
Liaoning & 0.42 & -0.03 & -0.19 & 0.22 & 0.21 & 10 \\
Hunan & 0.65 & -0.63 & -1.17 & 0.23 & 0.05 & 11 \\
Fujian & -0.01 & 0.19 & 0.07 & -0.09 & 0.04 & 12 \\
Hubei & 0.24 & -0.33 & -0.44 & 0.46 & 0.04 & 13 \\
Anhui & 0.00 & -0.54 & -0.02 & 0.46 & -0.08 & 14 \\
Shaanxi & -0.56 & 0.29 & 0.61 & 0.32 & -0.09 & 15 \\
Tianjin & -0.80 & 1.02 & -0.02 & 0.26 & -0.13 & 16 \\
Guangxi & -0.02 & -0.66 & -0.45 & 0.23 & -0.20 & 17 \\
Heilongjiang & -0.24 & -0.39 & -0.06 & 0.07 & -0.22 & 18 \\
Inner Mongolia & -0.65 & -0.54 & 1.59 & 0.15 & -0.24 & 19 \\
Chongqing & -0.93 & 0.05 & 1.76 & -0.22 & -0.26 & 20 \\
Jiangxi & -0.44 & -0.45 & 0.44 & -0.06 & -0.28 & 21 \\
Shanxi & -0.44 & -0.74 & -0.03 & 0.59 & -0.34 & 22 \\
Jilin & -0.35 & -0.46 & -0.51 & 0.10 & -0.35 & 23 \\
Yunnan & -0.36 & -0.62 & -0.42 & 0.30 & -0.35 & 24 \\
Xinjiang & -0.74 & -0.22 & -0.66 & 1.01 & -0.40 & 25 \\
Guizhou & -0.25 & -0.84 & -1.60 & 0.23 & -0.51 & 26 \\
Ningxia & -1.49 & 0.16 & 1.26 & -0.14 & -0.57 & 27 \\
Gansu & -0.61 & -0.68 & -1.05 & 0.03 & -0.61 & 28 \\
Hainan & -0.69 & -0.18 & 0.20 & -2.65 & -0.68 & 29 \\
Tibet & -1.09 & -0.16 & -0.64 & -0.17 & -0.70 & 30 \\
Qinghai & -0.80 & 0.21 & -0.19 & -3.71 & -0.81 & 31 \\
\hline
\end{tabular}

\section{The Labor Productivity of Government Departments}

Factor comprehensive score of each region:

$$
\hat{F}_{j}=\sum_{i=1} \frac{\lambda_{i}}{\lambda_{1}+\lambda_{2}+\cdots+\lambda_{m}} \hat{F}_{i} \quad(\mathrm{j}=1,2, \ldots \mathrm{n} ; \mathrm{i}=1,2, \ldots \mathrm{m})
$$


(1) It is not reasonable to consider using factor composite scores as the labor productivity of government department. The quality of factor composite scores is relatively overall, and negative rating does not mean that the government services play an inhibitory effect on the development of society.

(2) Comprehensive score of factor is real number with no range.

(3) The absolute value of factor score are smaller because of the standardized data.

Considering all factors, the labor productivity of government departments can be defined as follows:

$$
\rho=\alpha+\hat{F}_{j} * \beta \% \quad(\alpha, \beta \text { for nonnegative constant })
$$

When $\alpha, \beta$ are determined, the labor productivity are the linear transformation of composite scores. It does not change the score ranking, but also can ensure that the labor productivity of all government departments is non-negative, unless comprehensive scores are very small negative. A local government's comprehensive factor score is a small negative, then it is meaningless to count its output. $\alpha, \beta$ play the roles of regulating composite scores with no impact in ranking.

\subsection{Advantages and Disadvantages}

If account output of government departments by the cost, it will be easy to evaluate a local government departments as an efficient sector which has wasted much. However, after labor productivity combining with government fiscal expenditure performance evaluation score, it will greatly reduce such errors. And as the same time it can avoid inflating GDP because of excessive government spending.

However, labor productivity of government departments is not the labor productivity in the conventional sense, which only includes government performance evaluation information. So this sector output includes the fiscal expenditure performance information. Simultaneously, they are determined as appropriate, so they can affect the overall government sector output directly. And the value of sector output is not accurate, just a rough estimate.

\subsection{The Output of Local Government in 2011}

Table 8. Output calculation of local government

\begin{tabular}{|c|c|c|c|c|c|c|c|c|c|}
\hline Region & $F$ & $\rho_{1}$ & $p_{0}$ & $\mathcal{C}_{0}$ & $p_{1}$ & $\mathcal{C}_{1}$ & $\rho_{2}$ & $p_{2}$ & $C_{2}$ \\
\hline Guangdong & 1.63 & 1.16 & 6712.40 & 1 & 7809.31 & 1 & 1.33 & 8906.22 & 1 \\
\hline Jangsu & 1.36 & 1.14 & 6221.72 & 2 & 7067.84 & 2 & 1.27 & 7913.96 & 2 \\
\hline Shandong & 1.12 & 1.11 & 5002.07 & 3 & 5563.46 & 3 & 1.22 & 6124.86 & 3 \\
\hline Beijing & 0.70 & 1.07 & 3245.23 & 12 & 3471.16 & 11 & 1.14 & 3697.09 & 9 \\
\hline Zhejiang & 0.68 & 1.07 & 3842.59 & 8 & 4105.45 & 6 & 1.14 & 4368.32 & 6 \\
\hline Sichuan & 0.29 & 1.03 & 4674.92 & 4 & 4810.11 & 4 & 1.06 & 4945.30 & 4 \\
\hline Henan & 0.26 & 1.03 & 4248.82 & 5 & 4359.14 & 5 & 1.05 & 4469.47 & 5 \\
\hline Shanghai & 0.22 & 1.02 & 3914.88 & 6 & 4002.07 & 7 & 1.04 & 4089.26 & 7 \\
\hline Hebei & 0.21 & 1.02 & 3537.39 & 9 & 3612.44 & 9 & 1.04 & 3687.49 & 10 \\
\hline Liaoning & 0.21 & 1.02 & 3905.85 & 7 & 3987.10 & 8 & 1.04 & 4068.35 & 8 \\
\hline Hunan & 0.05 & 1.01 & 3520.76 & 10 & 3539.02 & 10 & 1.01 & 3557.28 & 11 \\
\hline Fujian & 0.04 & 1.00 & 2198.18 & 25 & 2207.34 & 22 & 1.01 & 2216.50 & 21 \\
\hline Hubei & 0.04 & 1.00 & 3214.74 & 13 & 3226.80 & 13 & 1.01 & 3238.85 & 13 \\
\hline Anhui & -0.08 & 0.99 & 3302.99 & 11 & 3275.90 & 12 & 0.98 & 3248.82 & 12 \\
\hline Shaanxi & -0.09 & 0.99 & 2930.81 & 15 & 2903.27 & 15 & 0.98 & 2875.72 & 14 \\
\hline Tianjin & -0.13 & 0.99 & 1796.33 & 26 & 1773.43 & 26 & 0.97 & 1750.53 & 26 \\
\hline Guangxi & -0.20 & 0.98 & 2545.28 & 19 & 2493.51 & 19 & 0.96 & 2441.74 & 19 \\
\hline Heilongjiang & -0.22 & 0.98 & 2794.08 & 17 & 2733.41 & 17 & 0.96 & 2672.74 & 17 \\
\hline $\begin{array}{l}\text { Inner } \\
\text { Mongolia }\end{array}$ & -0.24 & 0.98 & 2989.21 & 14 & 2918.60 & 14 & 0.95 & 2848.00 & 15 \\
\hline Chongqing & -0.26 & 0.97 & 2570.24 & 18 & 2504.44 & 18 & 0.95 & 2438.64 & 18 \\
\hline Jiangxi & -0.28 & 0.97 & 2534.60 & 20 & 2462.79 & 20 & 0.94 & 2390.99 & 20 \\
\hline Shanxi & -0.34 & 0.97 & 2363.85 & 21 & 2283.25 & 21 & 0.93 & 2202.65 & 22 \\
\hline Jilin & -0.35 & 0.97 & 2201.74 & 24 & 2125.24 & 25 & 0.93 & 2048.74 & 24 \\
\hline Yunnan & -0.35 & 0.96 & 2929.60 & 16 & 2825.75 & 16 & 0.93 & 2721.89 & 16 \\
\hline Xinjiang & -0.40 & 0.96 & 2284.49 & 22 & 2194.19 & 23 & 0.92 & 2103.90 & 23 \\
\hline Guizhou & -0.51 & 0.95 & 2249.40 & 23 & 2133.72 & 24 & 0.90 & 2018.04 & 25 \\
\hline Ningxia & -0.57 & 0.94 & 705.91 & 31 & 665.89 & 31 & 0.89 & 625.86 & 31 \\
\hline Gansu & -0.61 & 0.94 & 1791.24 & 27 & 1682.38 & 27 & 0.88 & 1573.51 & 27 \\
\hline Hainan & -0.68 & 0.93 & 778.80 & 29 & 725.64 & 29 & 0.86 & 672.49 & 29 \\
\hline Tibet & -0.70 & 0.93 & 758.11 & 30 & 705.36 & 30 & 0.86 & 652.61 & 30 \\
\hline Qinghai & -0.81 & 0.92 & 967.47 & 28 & 888.67 & 28 & 0.84 & 809.88 & 28 \\
\hline
\end{tabular}


F as factor comprehensive score; $\rho_{1}, \rho_{2}$ as labor productivity of government departments :

$$
\rho_{1}=1+F^{*} 10 \%, \quad \rho_{2}=1+F^{*} 20 \%
$$

$p_{0}$ as local government fiscal spending in 2011; $p_{1}, p_{2}$ as the output of local government in 2011:

$$
p_{1}=\rho_{1} * p_{0}, \quad p_{2}=\rho_{2} * p_{0}
$$

$c_{0}, c_{1}, c_{2}$ as the rankings of $p_{0}, p_{1}, p_{2} ; \triangle \mathrm{C}$ as Ranking change:

$$
\Delta C=\sum_{j=1}\left|c_{i j}-c_{0 j}\right| \quad j=1,2, \cdots, 31
$$

In the table, as $\alpha$ is determinated with the $\beta$ increasing, changes in the ranking will be bigger, which is reflection of labor productivity in the government sector's impact on local government output. Just make sure the $\alpha, \beta$ right, it can get a relatively appropriate output of local government departments. And $\Delta \mathrm{C}=20$ in the table 8 .

\section{Conclusion}

Beijing local fiscal expenditure is 324.523 billion yuan and its output is 369.709 billion yuan by labor productivity, so ranking raised three. However there are some local governments with lower labor productivity, and their output is less than the input, so the rankings reduced. If we continue to adjust the government labor productivity, the rankings of the low efficiency and high efficiency departments will be further widened. It is the meaning of accounting government departments output. Although the output accounted by this ideal is not accurate, it can reflect the effect of government services well.

\section{Acknowledgments}

This work was jointly supported by the National Social Science Foundation (no. 13BTJ009), Guangxi Key Laboratory of Spatial Information and Geomatics (nos.1103108-24, 1207115-27).

\section{References}

Cheng, S., \& Zhang, J. (2008). The study of Chinese local government fiscal expenditure efficiency (1978-2000). Chinese academy of social sciences, April, 65-78.

He, X. (2012). Multivariate statistical analysis (third edition). Beijing: China Renmin University Press, pp.58-225.

Jiang, P. (2011). The government output of the non-market services accounting related problems. Journal of statistical research, May, 9-16.

Wang, Y., \& Wang, K. (2002). A new idea of non-market services output accounting - the method of output index. Journal of statistics and information theory altar, May, 39-56.

\section{(cc) $\mathrm{BY}$}

This work is licensed under a Creative Commons Attribution 3.0 License. 